\title{
Pervasive Investigations of Critical Speed over Weight and Deflection Factors of Shaft Assembly in CNC Ball Screw System
}

\author{
Kuldeep Verma and R. M. Belokar \\ PEC University of Technology, Chandigarh 160012, India \\ Correspondence should be addressed to Kuldeep Verma; k83v27883@gmail.com
}

Received 3 April 2016; Revised 22 May 2016; Accepted 2 June 2016

Academic Editor: René J. Romero-Troncoso

Copyright ( 92016 K. Verma and R. M. Belokar. This is an open access article distributed under the Creative Commons Attribution License, which permits unrestricted use, distribution, and reproduction in any medium, provided the original work is properly cited.

The demand for higher productivity requires machine tools to work on the adequate critical speed to have faster and more accurate ball screw system. Ball screw affects severely over the higher rotation speed of the shaft in computer numeric control (CNC) machining centers. This paper deals with an approach to calculate the initial critical speed of the shaft. Critical speed requires significant attention due to its major use in the manufacturing sectors. The impacts of weight on the critical speed of shaft assembly have been analyzed from theoretical as well as analytical investigations. Additionally, we evaluated the impact of weight on the deflection of the shafts along with failure analysis of shafts with respect to critical speed. Further, we computed the results for critical speed based factor to enhance the accuracy of CNC machining centers. Finally, the analytical estimations have been carried out to prove the validity of our proposal.

\section{Introduction}

Research on the CNC machine tools is gaining considerable momentum in the recent years. There are many research efforts reported by different researchers to enhance the accuracy of $\mathrm{CNC}$ machining centers. A majority of $\mathrm{CNC}$ machining systems are using ball screw drive system. The effect of ball screw feed drive system must be addressed to improve the efficiency of CNC matching centers. Nevertheless, few researchers have focused on the critical speed of the shaft used in the ball screw system. Some of the initiatives in the field of CNC machine tools are as follows. $\mathrm{Xu}$ et al. [1] presented thermal error forecast and performance evaluation for an air cooled ball screw system. Kim et al. [2] reported damage prediction in the multistep forging process of subminiature screws. A study in precision grinding of screw rotors using CBN wheel was proposed by Wei et al. [3]. A relation establishing the correlation between feed velocity and preloading in ball screw drives was presented in [4]. An effort towards thermal error optimization modeling and real-time compensation on a CNC center was proposed by Hao et al. [5]. Robust compensation of elastic deformation in ball screw drives in the machine was reported by
Kamalzadeh et al. [6]. An effort towards the thermal issues on CNC machine tools was suggested in [7]. Yang et al. [8] proposed thermal error modeling and compensation for high motorized spindle in CNC machines. A new method based on homogeneous method was described in [9]. Fuzzy based clustering method for thermal error modeling using a thermal sensor was reported by Wang et al. [10]. Thermal displacement and decomposition method for optimization of an ultraprecision machine tool were shown in [11]. A thermal model of a ball screw feed drive system for a machine tool was presented by Min and Jiang [12]. An investigation based on Newton interpolation method for calculation of geometric and thermal error compensation for CNC milling machines was suggested by Wang et al. [13]. A study on heat generation based method for precision ball screw drive system was conducted by $\mathrm{Xu}$ et al. [14]. An initiative based on thermal deformation estimation for a hollow ball screw feed drive system was reported by Yang et al. [15]. Design and simulation of the gas-liquid binary cooling system for high-speed ball screw units were proposed by Liu et al. [16]. In the direction of stiffness, Olvera et al. [17] presented an analysis on the tool tip radial stiffness of turn-milling centers and proved its validity. Brecher and Witt [18] reported 
an interactive analysis of structure mechanic behavior of machine tools. Li et al. [19] studied reliability evaluation of NC machine tools considering working conditions. Sued and Pons [20] highlighted the dynamic interaction between machine, tool, and substrate in bobbin friction stir welding for CNC machines. For the heavy CNC machines, rotation through the idea of rack and pinion is avoided and ball screw system is used instead. This is due to the lower speed in rack and pinion mechanism as compared to ball screw systems. We focused on the critical speed parameter for our investigations. The critical speed of the shaft may be referred to as the maximum speed of shaft over and above which failure of the shaft could be occurred. Critical speed of the shaft remains different and depends on the calculation method. There are four major methods for supporting assembled shafts, namely, (i) fixed-fixed, (ii) fixed-free, (iii) fixed-supported, and (iv) supported-supported. We used the fourth method (i.e., supported-supported method) for our analytical investigations. The motivation behind the research work initiates from the frequent failure of the shafts at higher revolutions. The accurate critical speed of shafts remains the top priority for the performance assessment of $\mathrm{CNC}$ machines. An optimal speed of the shafts enhances the performance of the overall system whereas the strength of CNC machining system may be dependent on the same. Specific speed of a shaft may give the best result for a single instance, but we have to deploy such an efficient critical speed that provides optimal results in speed evaluations. The improper speeding strategy may change the behavior of shafts resulting in an overload of the entire system. This strategy can consume more resources in terms of both energy and computation resulting in the entire system performance degradation. There always remains dire influence of critical speed assessment on the entire operating environment when evaluating a specific speed of shafts of CNC systems. The goal remains there is to carefully choose and examine the speed for shafts and present an optimal result without compromising any constraints than expected outcome. Therefore, a typical investigation should be required to access the critical speed of shafts for CNC machines. In this paper, a well-defined approach is suggested to calculate the initial critical speed of the shaft which serves as an integral component of the ball screw system.

The rest of the paper is organized in the following sections. Section 2 reported the critical speed based computation method for ball screw systems. Section 3 presented the problem definition and system model. Section 4 describes the detailed design of our experimental setup. Analytical results and validations are presented and discussed in Section 5. Finally, conclusions are made in Section 6.

\section{Proposed Model for Critical Speed Calculation}

This section represents the motivations along with mathematical equations for critical speed calculation. We used the following notions to calculate the critical speed of the shaft. The methods given in our proposal are applicable for shaft supporting at two points only and for the first critical speed. The higher critical speeds and the critical speeds of shafts supported at more than two points are generally high to exclude them from consideration. Let Ma denote the moment of area of cross section in bending $\left(\mathrm{mm}^{4}\right)$; SL represents the length of shaft (mm), CS shows the critical speed (rpm), $\mathrm{Wt}$ depicts the weight of shaft per unit length $(\mathrm{kg} / \mathrm{mm})$, and $d$ exhibits deflection of the shaft $(\mathrm{mm})$. Practically, the following two cases may arise.

2.1. First Case. For a shaft of the almost uniform cross section and the gears mounted on it are of negligible weight compared to the weights of shafts [21], then the first critical speed (CS) is given by

$$
\mathrm{CS}=C \sqrt{\frac{\mathrm{Ma}}{\mathrm{Wt} \mathrm{SL}^{4}}} \mathrm{rpm},
$$

where $C$ denotes constant for different shaft supports, namely, cantilever, simple supported and fixed, and so forth. We assumed the steel shaft with parameter as $E=21 \times 10^{3} \mathrm{~kg} / \mathrm{mm}^{2}$ and $g=9810 \mathrm{~mm} / \mathrm{sec}^{2}$. Ma for a different shaft cross section can be obtained from shaft calculation standard.

2.2. Second Case. For a shaft of negligible mass and having weights $\mathrm{Wt}_{1}, \mathrm{Wt}_{2}, \ldots, \mathrm{Wt}_{n}$ on it, the first critical speed [21] is given by

$$
\mathrm{CS}=945 \sqrt{\frac{\sum_{i=1}^{n} \mathrm{Wt} \mathrm{ds}}{\sum_{i=1}^{n}(\mathrm{Wt} \mathrm{ds})^{2}}} \mathrm{rpm},
$$

where $\mathrm{ds}_{1}, \mathrm{ds}_{2}, \ldots, \mathrm{ds_{n }}$ are the static deflections of the shafts at the weights. If the weight of the shaft is considerable, then it is divided into several parts (a number of which are dependent on designer discretion). The weight of each part is lumped at a point and added to the external weights. Then, as before the static deflections $\mathrm{ds}_{1}, \mathrm{ds}_{2}, \ldots, \mathrm{ds}_{n}$ of the shaft at the points of action of the lumped weights can be found out and the critical speed can be determined from the above said formula. The same procedure can be adopted to find out the critical speed of a shaft with varying cross section under its own weight.

2.3. Critical Speed Calculation. The critical speed of the shaft under its own weight and the gears weight is found as follows [21]. We assumed that the shaft is simply supported and gear hubs do not add flexural rigidity to the shaft. We followed the following steps to calculate the critical speed of the shaft. (i) The weights of the gears and different portions of the shaft are found out. (ii) The bending moment due to the weights and the second moment of area in bending are calculated at different sections and the M/EI diagram for the shaft is constructed.With the help of the above two steps on the ME/I diagram, the funicular polygon is constructed. The pole distance $\mathrm{H} 1$ is arbitrary. By drawing lines parallel to those in the funicular polygon, the slope diagram is constructed. A second funicular polygon is constructed from the slope diagram taking an arbitrary pole distance $\mathrm{H} 2$. 
TABLE 1: Scenario parameters.

\begin{tabular}{|c|c|}
\hline Scenario parameters & Value \\
\hline Shaft length & $500 \mathrm{~mm}$ \\
\hline Load points & 8 \\
\hline Load positions & $\begin{array}{c}50 \mathrm{~mm}, 100 \mathrm{~mm}, 170 \mathrm{~mm}, 240 \mathrm{~mm} \\
300 \mathrm{~mm}, 380 \mathrm{~mm}, 440 \mathrm{~mm} \text {, and } 500 \mathrm{~mm}\end{array}$ \\
\hline Shaft diameter & $\begin{array}{l}\text { Variable ( } 50 \mathrm{~mm} \text { for the first two points, } \\
100 \mathrm{~mm} \text { for the next four points, and } \\
80 \mathrm{~mm} \text { for the last two points) }\end{array}$ \\
\hline Weight cycles & 5 \\
\hline Deflection cycle & 6 \\
\hline $\begin{array}{l}\text { Weight deflection } \\
\text { cycle }\end{array}$ & 5 \\
\hline Machine type & CNC machining center \\
\hline Bearing & Single-row angular contact \\
\hline
\end{tabular}

By drawing lines parallel to those in the second funicular polygon, the deflection diagram is constructed. The line joining the intersections of the deflection curve with the bearing centerlines gives the zero-deflection line. Parallel to this zero-deflection line, a line is drawn in the second funicular polygon. The line corresponding to this in the slope diagram gives the zero-slope line. The scales of the slope and deflection diagrams are obtained and shown in Section 6.

\section{Problem Definition and System Model}

When the speed of rotation approached high level the shaft may resonate and eventually become unable to operate due to the natural frequency of the shaft. Therefore, it becomes necessary to strengthen shaft speed limit or run the shaft up to specified critical speed. Over and above this limit, the shaft may be unable to operate. In our analysis, a shaft simply supported at both ends with gears mounted over has been taken. Accordingly, for a given feed drive system, we are interested in finding the following two problems: (i) what is the influence of weight and deflection cycle on the performance of the feed drive system and (ii) how to calculate the critical speed of shaft in a feed drive system with comparative analysis of weight versus deflection cycles. We used the mathematical model based on the above-mentioned equations (1) and (2) for our investigations.

\section{Detailed Setup}

The following assumptions have been incorporated in our evaluation model. We have taken ball screw system with shaft length $500 \mathrm{~mm}$ supported at eight points. The shaft support points are at $50 \mathrm{~mm}, 100 \mathrm{~mm}, 170 \mathrm{~mm}, 240 \mathrm{~mm}, 310 \mathrm{~mm}$, $380 \mathrm{~mm}, 440 \mathrm{~mm}$, and $500 \mathrm{~mm}$, respectively. We applied load (kg) ranging from 0.6 to 1.0 at point $50 \mathrm{~mm}$, from 6.1 to 10.5 at point $100 \mathrm{~mm}$, from 4.2 to 5.7 at point $170 \mathrm{~mm}$, from 4.25 to $5.75 \mathrm{~mm}$ at point $240 \mathrm{~mm}$, from 4.2 to $5.7 \mathrm{~mm}$ at point $300 \mathrm{~mm}$, from 4.25 to $5.75 \mathrm{~mm}$ at point $380 \mathrm{~mm}$, from 13.2 to $21.59 \mathrm{~mm}$ at point $440 \mathrm{~mm}$, and from 3.00 to $3.71 \mathrm{~mm}$ at point $500 \mathrm{~mm}$. The summarization of the parameters of our proposed model is given in Table 1.

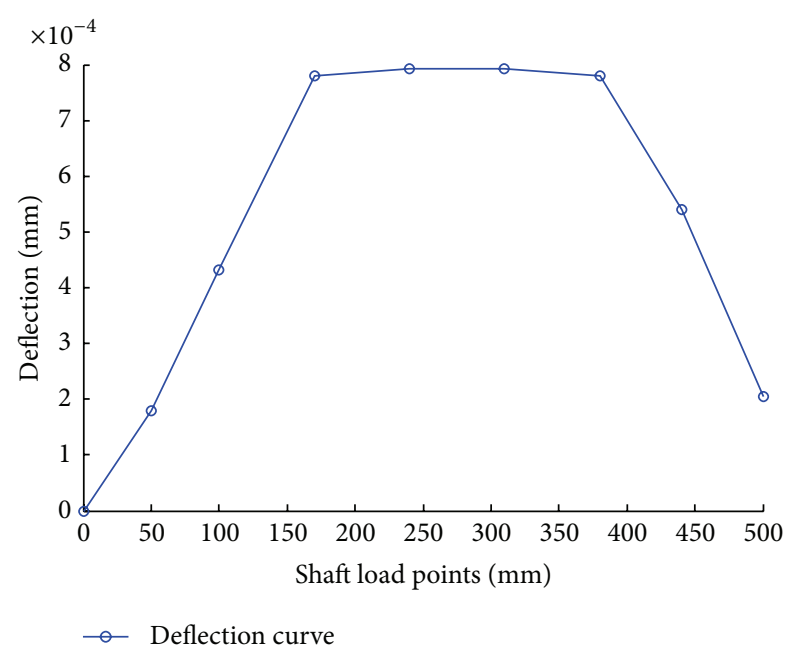

Figure 1: Graph of deflection versus shaft length load points initial analysis.

\section{Analytical Results and Validations}

This section enables us to implement and evaluate our proposed model for critical speed evaluation. We evaluated the performance evaluation of our model based on three factors, namely, deflection curve, weight cycle, and critical speed. Initially, we calculate the deflection curve for the shaft of the ball screw system. Next, we computed the weight cycle of the shaft for our proposed system. Finally, we made a comparative analysis of deflection versus weight cycle for the investigations.

5.1. Deflection Cycle Analysis. We calculated the deflection value corresponding to the load points on the shaft of the ball screw system. The deflection curve for our proposed model is shown in Figure 1.

It has been observed from Figure 1 that the value of deflection remains minimum at the end point of the shaft. At the center of the shaft, the deflection value remains maximum due to the load value affect more at the center as compared to the edges of the shaft. Next, we extended the deflection evaluation for six cycles as shown in Figure 2. We found that the deflection curve is showing linear elliptical behavior for all six cycles. We observed that the value of deflection remains minimum at all the beginning and ending points of the shaft, that is, $50 \mathrm{~mm}$ and $500 \mathrm{~mm}$. The deflection value remains maximum for shaft points at center, that is, $240 \mathrm{~mm}$ and $310 \mathrm{~mm}$. This is due to the fact that maximum deflection occurred at the center if the shaft remains supported at both ends. This seems to show a good agreement with the results reported in [8]. Yang et al. [8] worked over thermal error modeling and compensation for a high-speed motorized spindle. We worked for the deflection cycles and weight cycles with respect to the critical speed of our proposed model. This makes our work more consistent with the findings of [8].

5.2. Weight Cycle Analysis. Further, we calculated the load values on different points of the shaft for weight path 


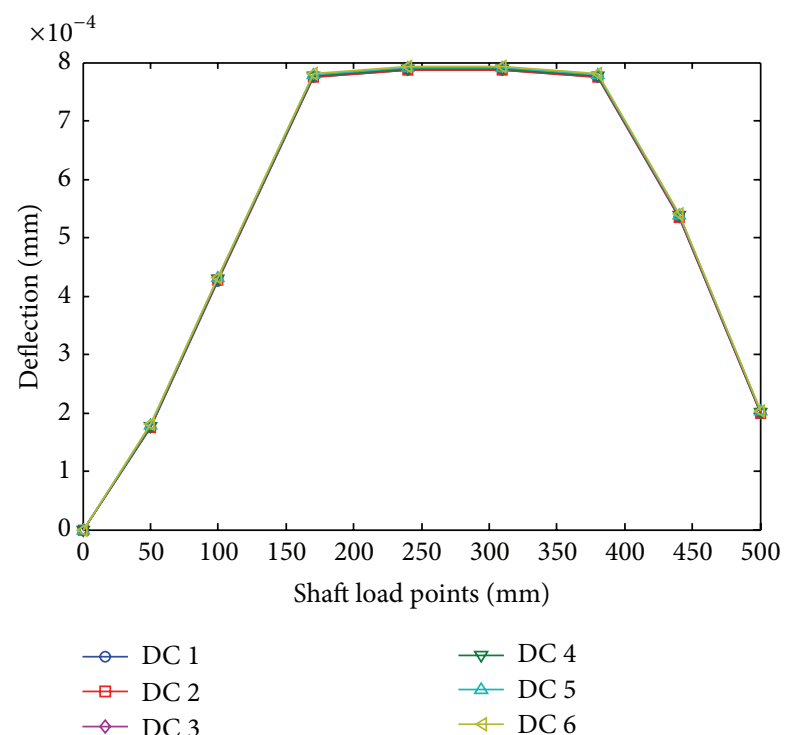

FIGURE 2: Comprehensive deflection cycles analysis.

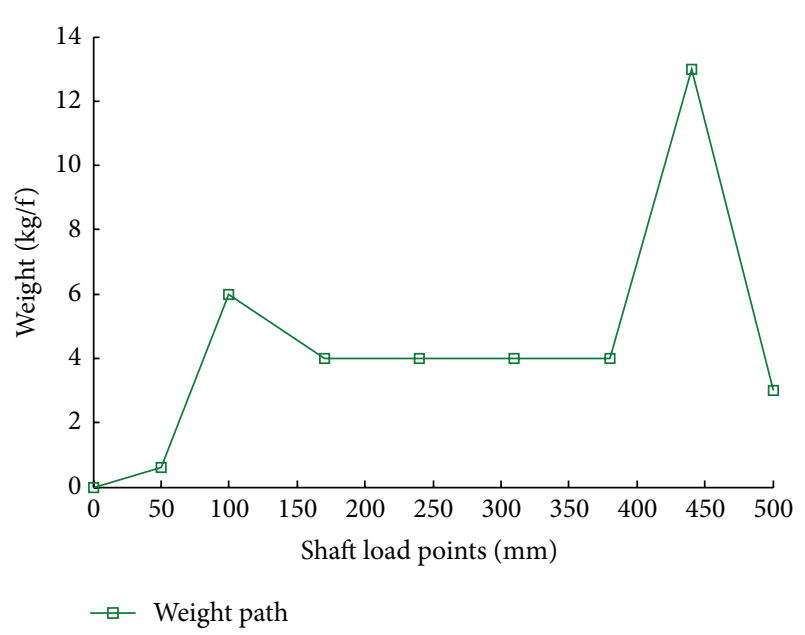

FIGURE 3: Graph of weight versus shaft length load point initial analysis.

calculation as shown in Figure 3. It has been observed that the load value at point $50 \mathrm{~mm}$ remains minimum as compared to another. The value of load increases up to point $100 \mathrm{~mm}$; afterward it declines up to point $170 \mathrm{~mm}$. The load value remains constant on the points $170 \mathrm{~mm}, 240 \mathrm{~mm}, 310 \mathrm{~mm}$, and $380 \mathrm{~mm}$. The load value remained maximum for a point at $440 \mathrm{~mm}$ and, afterwards, it declines for a point at $500 \mathrm{~mm}$. We extended this evaluation for six weight cycles and observed the consistent behavior as we observed in the case of weight path analysis.

Figure 4 depicts the weight cycle analysis for the shaft of the feed drive system. We noticed that the load value remains maximum for the sixth weight cycle and the minimum for the first cycle. This is due to the fact that if we apply load on the shaft, the deflection remains minimum for the first cycle and maximum for the last cycle which remained true in our case too.

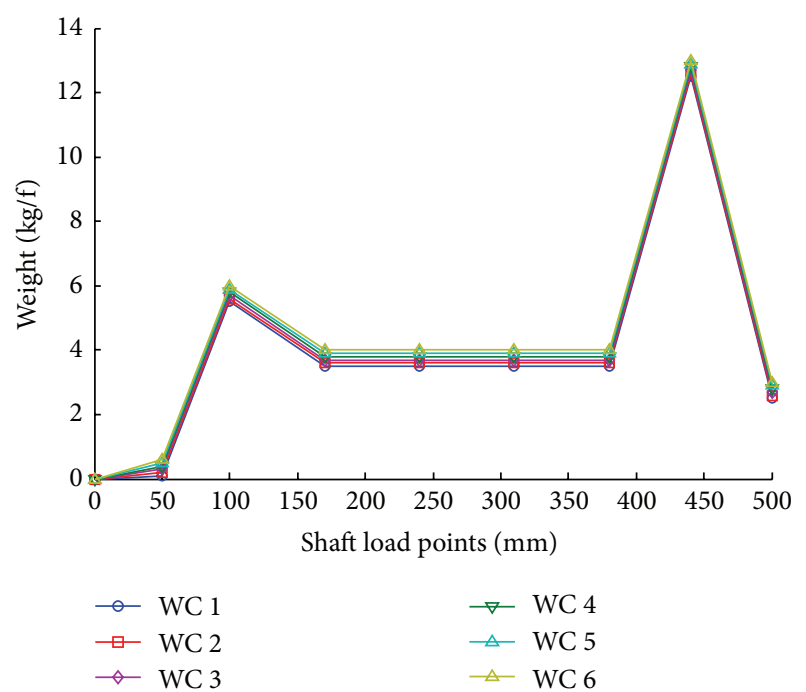

FIGURE 4: Comprehensive weight cycles analysis.

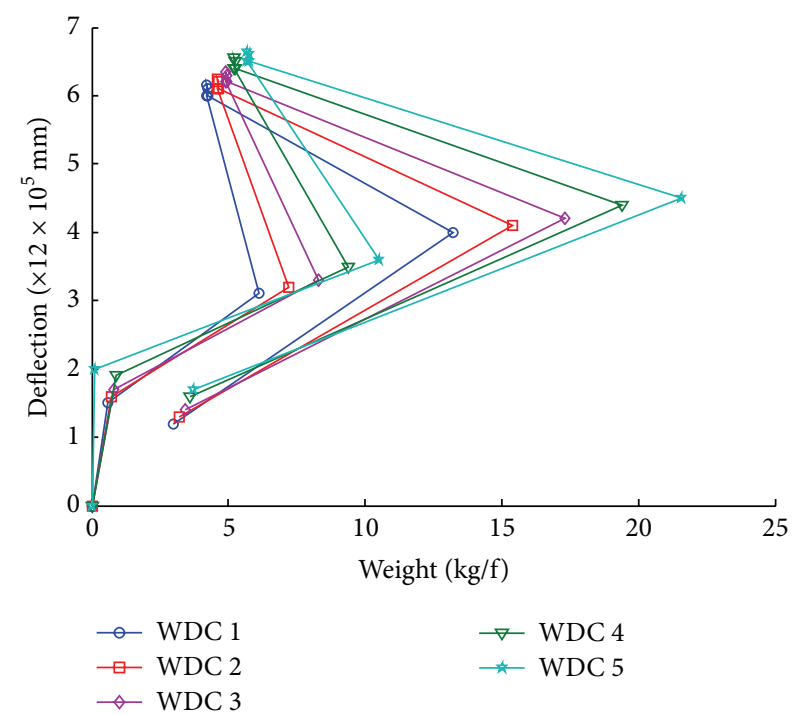

FIGURE 5: Graph of weight versus deflection cycles analysis.

Sheng et al. [22] presented research on key technologies of unit-based CNC machine tool assembly design. This seems consistent with the results reported in Figure 4 highlighting inclusive investigations of weight versus shaft load cyclic analysis.

5.3. Weight Deflection Cycle Evaluation. Lastly, we focused on the comparative evaluation of weight and deflection on the single platform for our proposed model. We made an integrated evaluation of weight versus deflection and observed a nonlinear cyclic behavior as shown in Figure 5. We observed that the deflection and load value remained maximum for fifth weight deflection cycle.

We proposed a more robust framework subsuming a wider range of investigations as deflection curve, deflection 
TABLE 2: Critical speed summarization.

\begin{tabular}{|c|c|c|c|c|c|c|c|c|}
\hline Shaft load points (mm) & 50 & 100 & 170 & 240 & 310 & 380 & 440 & 500 \\
\hline Weight (kgf) & 0.6 & 6.1 & 4.2 & 4.25 & 4.2 & 4.25 & 13.2 & 3.0 \\
\hline Deflection $\left(\times 12 \times 10^{-5} \mathrm{~mm}\right)$ & 1.5 & 3.1 & 6 & 6.1 & 6.15 & 6 & 4 & 1.2 \\
\hline Critical speed (rpm) & \multicolumn{8}{|c|}{38467 using (2) } \\
\hline Weight (kgf) & 0.7 & 7.2 & 4.6 & 4.65 & 4.6 & 4.65 & 15.4 & 3.21 \\
\hline Deflection $\left(\times 12 \times 10^{-5} \mathrm{~mm}\right)$ & 1.6 & 3.2 & 6.1 & 6.2 & 6.25 & 6.1 & 4.1 & 1.3 \\
\hline Critical speed (rpm) & \multicolumn{8}{|c|}{38316 using (2) } \\
\hline Weight (kgf) & 0.8 & 8.3 & 4.9 & 4.95 & 4.9 & 4.95 & 17.3 & 3.41 \\
\hline Deflection $\left(\times 12 \times 10^{-5} \mathrm{~mm}\right)$ & 1.7 & 3.3 & 6.2 & 6.3 & 6.35 & 6.2 & 4.2 & 1.4 \\
\hline Critical speed $(\mathrm{rpm})$ & \multicolumn{8}{|c|}{38082 using (2) } \\
\hline Weight (kgf) & 0.9 & 9.4 & 5.2 & 5.25 & 5.2 & 5.25 & 19.4 & 3.61 \\
\hline Deflection $\left(\times 12 \times 10^{-5} \mathrm{~mm}\right)$ & 1.8 & 3.4 & 6.3 & 6.4 & 6.45 & 6.3 & 4.3 & 1.5 \\
\hline Critical speed (rpm) & \multicolumn{8}{|c|}{37870 using (2) } \\
\hline Weight (kgf) & 1.0 & 10.5 & 5.7 & 5.75 & 5.7 & 5.75 & 21.59 & 3.71 \\
\hline Deflection $\left(\times 12 \times 10^{-5} \mathrm{~mm}\right)$ & 1.9 & 3.5 & 6.4 & 6.5 & 6.55 & 6.4 & 4.4 & 1.6 \\
\hline Critical speed (rpm) & \multicolumn{8}{|c|}{37563 using (2) } \\
\hline
\end{tabular}

cycle, weight path, and weight cycles and integrated deflection and weight cycle evaluation on a single platform. This shows better agreement with the results reported in [23]. Xu et al. [23] presented a novel approach for high-speed/highprecision ball screw system. Also, the authors in [23] focused on the positioning accuracy and evaluated the significance of nut air cooling ball screw drive system. Further, Liu et al. [24] proposed thermal error modeling method for a CNC machine tool feed drive system. We extended the work of [23, 24 ] by finding the critical speed of the shaft of the ball screw system making our work more robust and efficient. Finally, we calculated the critical speed of the shaft corresponding to the weight and deflection as shown in Table 2. We observed that critical speed shows a decline in behavior with load increment on the different points of the shaft in ball screw systems.

Overall, all the graphs reflect linear, progressive behaviors and show a strong relationship between deflection and load factor on the shaft of the ball screw system in CNC machining centers. This analysis shows that load factor with respect to deflection severely affects the performance of the ball screw system in CNC machining centers.

\section{Conclusions}

This paper proposed an evolutionary method to calculate the critical speed of the shaft of ball screw systems. We performed analytical investigation for computation of critical speed of the shaft. We observed that the estimations in our study are more practical in nature. The results from our proposed methodology reveal that there always remains a considerable separation among theoretical and practical aspects in machining and manufacturing areas. We stressed on four major directions.

(i) Firstly, we evaluated the deflection path and deflection analysis of shaft in the ball screw system. (ii) Secondly, we investigated the weight path and weight cycles in our proposed model.

(iii) Next, the same model is evaluated for comparative analysis of weight and deflection cycles.

(iv) Finally, we calculated the initial critical speed of the shaft with respect to deflection and load values in our proposed model.

In the future, we would like to investigate the ball screw system from a new facet like deformation, material strength, optimization, and so forth. Finally, this work allows us to analytically formulate the investigation strategies under the ball screw system shaft and therefore provides insight for directing the designated model for CNC machining.

\section{Competing Interests}

The authors declare that there is no conflict of interests regarding the publication of this paper.

\section{References}

[1] Z. Z. Xu, X. J. Liu, H. K. Kim, J. H. Shin, and S. K. Lyu, “Thermal error forecast and performance evaluation for an air-cooling ball screw system," International Journal of Machine Tools and Manufacture, vol. 51, no. 7-8, pp. 605-611, 2011.

[2] J.-B. Kim, W.-S. Seo, and K. Park, "Damage prediction in the multistep forging process of subminiature screws," International Journal of Precision Engineering and Manufacturing, vol. 13, no. 9, pp. 1619-1624, 2012.

[3] J. Wei, Q. Zhang, Z. Xu, and S. Ki Lyu, "Study on precision grinding of screw rotors using CBN wheel," International Journal of Precision Engineering and Manufacturing, vol. 11, no. 5, pp. 651-658, 2010.

[4] A. Verl and S. Frey, "Correlation between feed velocity and preloading in ball screw drives," CIRP Annals-Manufacturing Technology, vol. 59, no. 2, pp. 429-432, 2010. 
[5] W. Hao, Z. Hongtao, G. Qianjian, W. Xiushan, and Y. Jianguo, "Thermal error optimization modeling and real-time compensation on a CNC turning center," Journal of Materials Processing Technology, vol. 207, no. 1-3, pp. 172-179, 2008.

[6] A. Kamalzadeh, D. J. Gordon, and K. Erkorkmaz, "Robust compensation of elastic deformations in ball screw drives," International Journal of Machine Tools and Manufacture, vol. 50, no. 6, pp. 559-574, 2010.

[7] J. Mayr, J. Jedrzejewski, E. Uhlmann et al., "Thermal issues in machine tools," CIRP Annals-Manufacturing Technology, vol. 61, no. 2, pp. 771-791, 2012.

[8] J. Yang, H. Shi, B. Feng, L. Zhao, C. Ma, and X. S. Mei, “Thermal error modeling and compensation for a high-speed motorized spindle," International Journal of Advanced Manufacturing Technology, vol. 77, no. 5, pp. 1005-1017, 2015.

[9] E. Díaz-Tena, U. Ugalde, L. N. López De Lacalle, A. De La Iglesia, A. Calleja, and F. J. Campa, "Propagation of assembly errors in multitasking machines by the homogenous matrix method," International Journal of Advanced Manufacturing Technology, vol. 68, no. 1-4, pp. 149-164, 2013.

[10] H. T. Wang, L. P. Wang, T. M. Li, and J. Han, "Thermal sensor selection for the thermal error modeling of machine tool based on the fuzzy clustering method," International Journal of Advanced Manufacturing Technology, vol. 69, no. 1, pp. 121-126, 2013.

[11] Y. C. Liang, H. Su, L. H. Lu, W. Q. Chen, Y. Z. Sun, and P. Zhang, "Thermal optimization of an ultra-precision machine tool by the thermal displacement decomposition and counteraction method," International Journal of Advanced Manufacturing Technology, vol. 76, no. 1-4, pp. 635-645, 2014.

[12] X. Min and X. Jiang, "A thermal model of a ball screw feed drive system for a machine tool," Proceedings of the Institution of Mechanical Engineers, Part C: Journal of Mechanical Engineering Science, vol. 225, no. 1, pp. 186-193, 2011.

[13] W. Wang, Y. Zhang, J. Yang, Y. Zhang, and F. Yuan, "Geometric and thermal error compensation for $\mathrm{CNC}$ milling machines based on Newton interpolation method," Proceedings of the Institution of Mechanical Engineers, Part C, vol. 227, no. 4, pp. 771-778, 2013.

[14] Z. Z. Xu, X. J. Liu, I. B. Lee, I. S. Ahn, and S. K. Lyu, "A study on heat generation control of a precision ball screw drive system," Advanced Materials Research, vol. 680, pp. 360-363, 2013.

[15] A. S. Yang, S. Z. Cai, S. H. Hsieh et al., "Thermal deformation estimation for a hollow ball screw feed drive system," in Proceedings of the World Congress on Engineering (WCE '13), vol. 3, pp. 2047-2052, July 2013.

[16] Y. P. Liu, Z. Chen, and Z. Y. Rui, "Design and simulation of gasliquid binary cooling system for high-speed ball screw units," China Mechanical Engineering, vol. 24, no. 1, pp. 95-98, 2013.

[17] D. Olvera, L. N. López De Lacalle, F. I. Compeán, A. FzValdivielso, A. Lamikiz, and F. J. Campa, "Analysis of the tool tip radial stiffness of turn-milling centers," The International Journal of Advanced Manufacturing Technology, vol. 60, no. 912, pp. 883-891, 2012.

[18] C. Brecher and S. Witt, "Interactive analysis of the structural mechanic behaviour of machine tools," Production Engineering, vol. 3, no. 4-5, pp. 475-481, 2009.

[19] H. Li, Z. Yang, B. Xu, C. Chen, Y. Kan, and G. Liu, "Reliability evaluation of NC machine tools considering working conditions," Mathematical Problems in Engineering, vol. 2016, Article ID 9842607, 11 pages, 2016.
[20] M. K. Sued and D. J. Pons, "Dynamic interaction between machine, tool, and substrate in bobbin friction stir welding," International Journal of Manufacturing Engineering, vol. 2016, Article ID 8697453, 14 pages, 2016.

[21] F. S. Tse, I. F. Morse, and R. T. Hinkle, Mechanical Vibrations, Prentice-Hall of India, 1985.

[22] Z. Sheng, L. Zhang, H. Xie, and C. Liu, "Research on key technologies of unit-based CNC machine tool assembly design," Mathematical Problems in Engineering, vol. 2014, Article ID 191069, 12 pages, 2014.

[23] Z.-Z. Xu, X.-J. Liu, C.-H. Choi, and S.-K. Lyu, "A novel high speed/high precision ball screw," International Journal of Precision Engineering and Manufacturing, vol. 14, no. 1, pp. 165167, 2013.

[24] K. Liu, M. Sun, Y. Wu, and T. Zhu, “Thermal error modeling method for a CNC machine tool feed drive system," Mathematical Problems in Engineering, vol. 2015, Article ID 436717, 6 pages, 2015. 


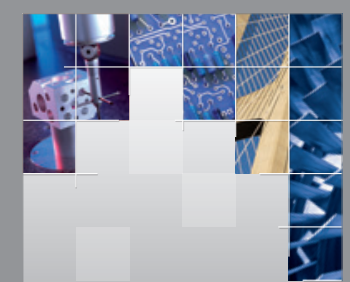

\section{Enfincering}
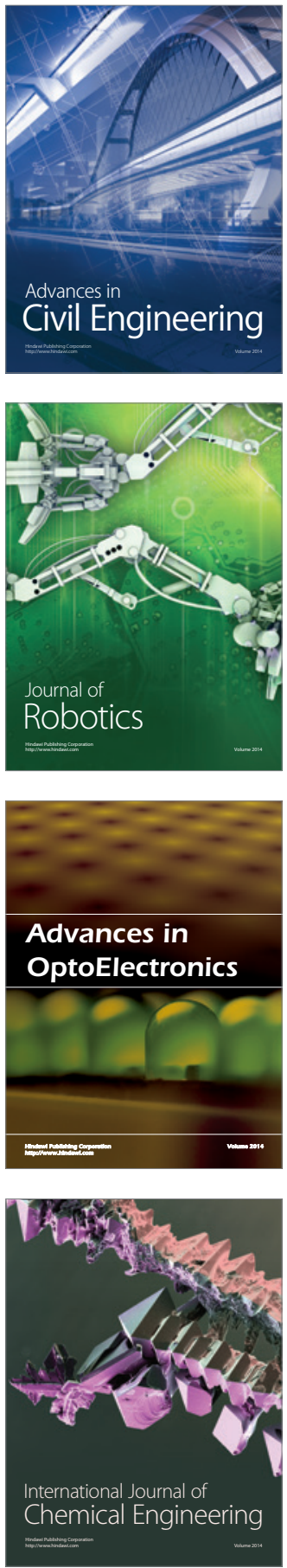

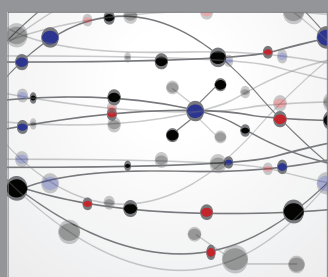

The Scientific World Journal

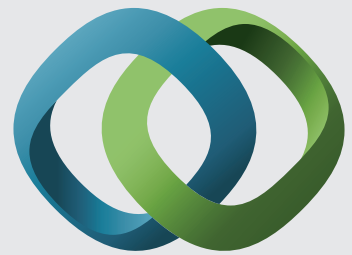

\section{Hindawi}

Submit your manuscripts at

http://www.hindawi.com
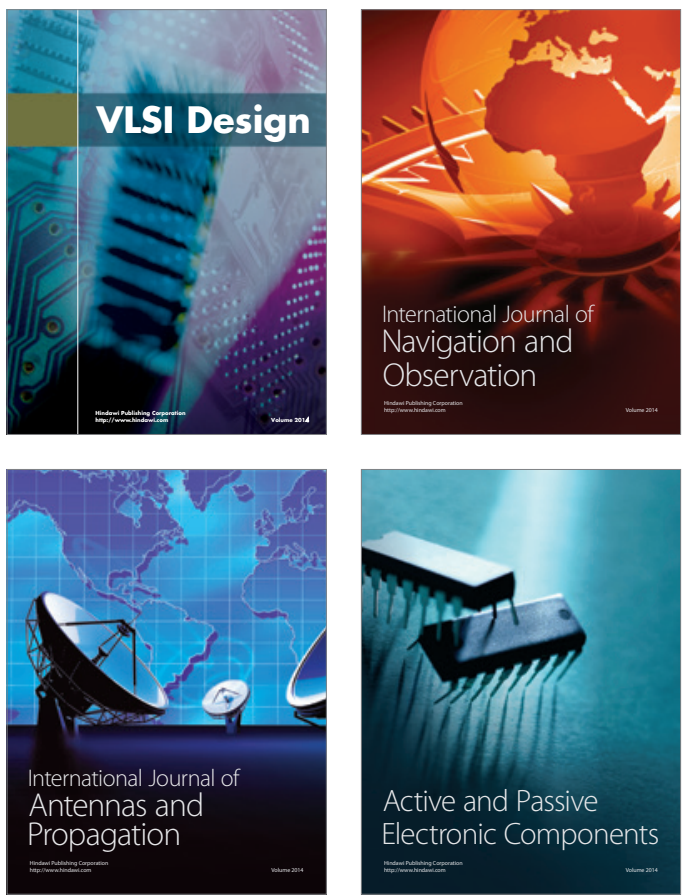
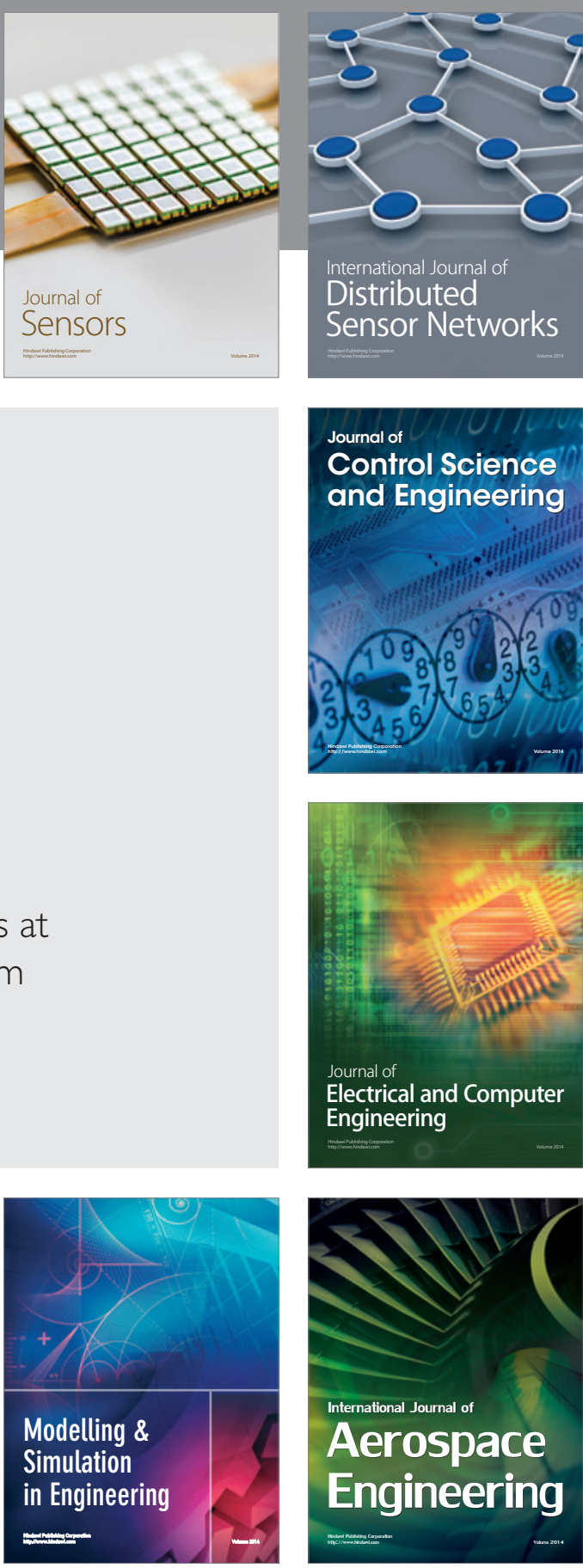

International Journal of

Distributed

Sensor Networks

Journal of

Control Science

and Engineering
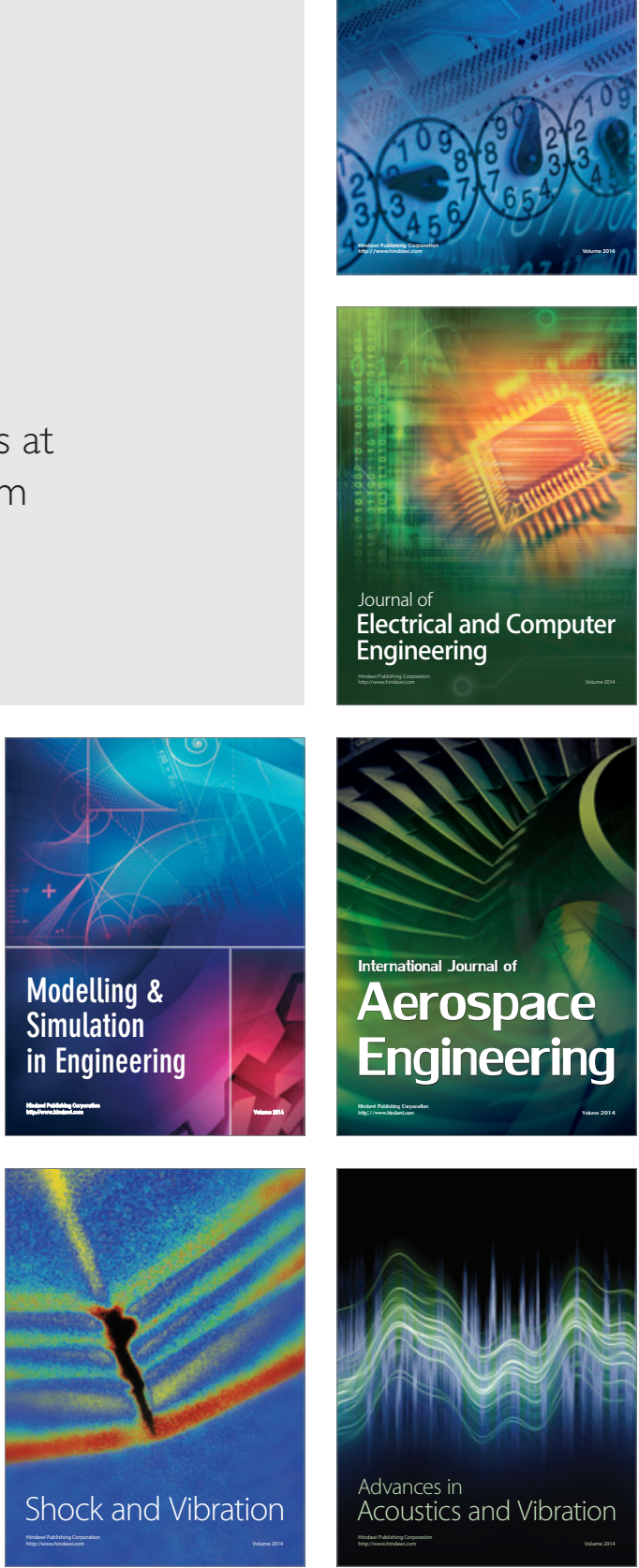